\title{
Recurrent Lymphoma
}

National Cancer Institute

\section{Source}

National Cancer Institute. Recurrent Lymphoma. NCI Thesaurus. Code C134157.

The reemergence of a lymphoma after a period of remission. 